7th International Symposium on Superalloy 718 and Derivatives Edited by: E.A. Ott, J.R. Groh, A. Banik, I. Dempster, T.P. Gabb, R. Helmink, X. Liu, A. Mitchell, G.P. Sjöberg, and A. Wusatowska-Sarnek TMS (The Minerals, Metals \& Materials Society), 2010

\title{
EFFECT OF SERRATED GRAIN BOUNDARIES ON THE CREEP PROPERTY OF INCONEL 718 SUPERALLOY
}

\author{
An-Chou Yeh ${ }^{1}$; Kang-Wei Lu ${ }^{1}$; Chen-Ming Kuo ${ }^{1 *}$; Hui-Yun Bor ${ }^{2}$; Chao-Nan Wei ${ }^{2}$ \\ ${ }^{1}$ Department of Mechanical and Automation Engineering, I-Shou University; \\ 1, Sec. 1, Syuecheng Rd.; Dashu, Kaohsiung, 84001, Taiwan, ROC \\ ${ }^{2}$ Materials and Electro-Optics Research Division, Chung-Shan Institute of Science and \\ Technology; P.O. Box 90008-8-4; Lungtan, Taoyuan 32599, Taiwan, ROC
}

Keywords: IN718, Zigzag morphology grain boundary, Creep

\begin{abstract}
The present study investigates the effect of serrated grain boundary with zigzag morphology on the high temperature creep deformation of IN718 superalloy. The experimental results have indicated that the morphology of grain boundary can be a function of heat-treatment condition. Experimental work includes XRD, DSC analysis, and SEM microstructure observations in order to investigate the underlying mechanism for the formation of zigzag grain boundary. Creep test under $650^{\circ} \mathrm{C} / 625 \mathrm{MPa}$ has been conducted on samples of IN718 with and without zigzag grain boundaries in order to determine its effects on deformation mechanisms. In conclusions, an improvement of 400 hours creep rupture life has been attributed by the serrated grain morphology.
\end{abstract}

\section{Introduction}

Traditional alloy development programmes with the addition of refractory elements have been reduced significantly in recent years due to the associated high costs of raw materials. A wide range of commercial alloys, with compositions tailored to particular applications, is readily available and advances in performance can be gained through improvements in processing to further explore the full benefit of its compositions [1-3]. Nickel-iron based superalloy, IN718, is the most widely used superalloy for its good strength, corrosion resistance and weldability as well as for its long-time stability up to $650^{\circ} \mathrm{C}$. IN718 is a precipitation-strengthened superalloy with microstructure containing various phases such as $\gamma, \gamma^{\prime \prime}, \gamma^{\prime}, \delta$, and MC carbides. Previous researches have proposed that heat treatment induced serrated grain boundary in IN718 and result improvement in its mechanical properties [4-7].

The aim of present study is to investigate the underlying mechanism for the formation of zigzag grain morphology and its effect on the creep rupture behaviour of IN718 under $650^{\circ} \mathrm{C} / 625 \mathrm{MPa}$.

\section{Experimental Procedure}

A cylindrical bar of IN718 with $2 \mathrm{~m}$ in length and $12.8 \mathrm{~mm}$ in diameter were obtained from Huntington Alloys. The average grain size of as-received sample is $25 \mu \mathrm{m}$ [8]. The chemical composition is given in table I. 
The cylindrical bar was then divided into two sets of samples for subsequently different heat treatments. One batch was treated with the $850^{\circ} \mathrm{C} / 4$ hours ageing followed by solutionizing temperature at $1095^{\circ} \mathrm{C}$ without cooling to room temperature in order to promote the formation of serrated grain boundary, this set of samples was designated SE.

Another batch had its $850^{\circ} \mathrm{C} / 4$ hours ageing temperature carried out separately from the solution heat treatment, and this set of samples was designated NS. Figures 1 and 2 illustrate the heat treatment cycle for SE and NS samples, respectively.

Table I. Chemical composition of IN718 (wt\%)

\begin{tabular}{|c|c|c|c|c|c|c|c|}
\hline $\mathrm{C}$ & $\mathrm{Mn}$ & $\mathrm{Fe}$ & $\mathrm{S}$ & $\mathrm{Si}$ & $\mathrm{Cu}$ & $\mathrm{Ni}$ & $\mathrm{Cr}$ \\
\hline 0.04 & 0.09 & 18.64 & 0.0001 & 0.07 & 0.17 & $\mathrm{Bal}$ & 18.11 \\
$\mathrm{Al}$ & $\mathrm{Ti}$ & $\mathrm{Co}$ & $\mathrm{Mo}$ & $\mathrm{Nb}$ & $\mathrm{Ta}$ & $\mathrm{P}$ & $\mathrm{B}$ \\
\hline 0.53 & 0.95 & 0.21 & 3.03 & 5.05 & 0.01 & 0.009 & 0.003 \\
\hline
\end{tabular}

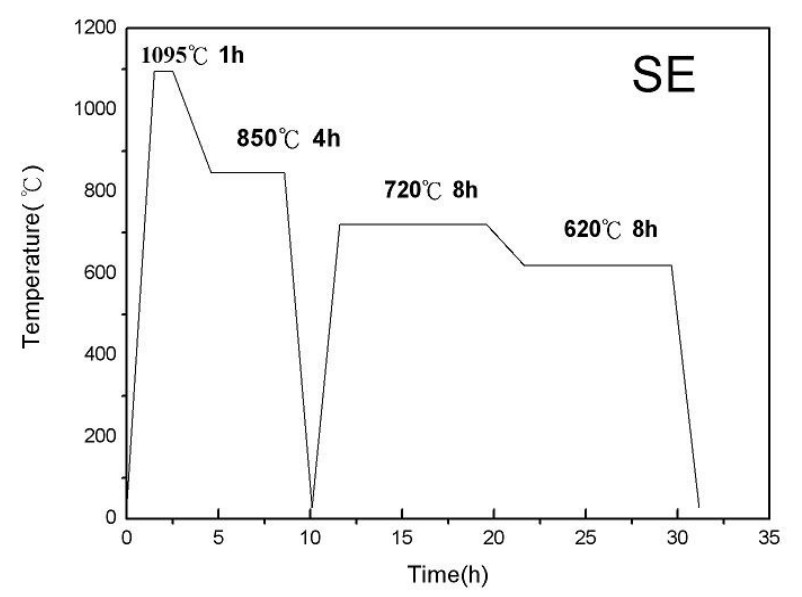

Figure1. The solution and ageing heat treatment cycle for SE samples to produce serrated grain boundary.

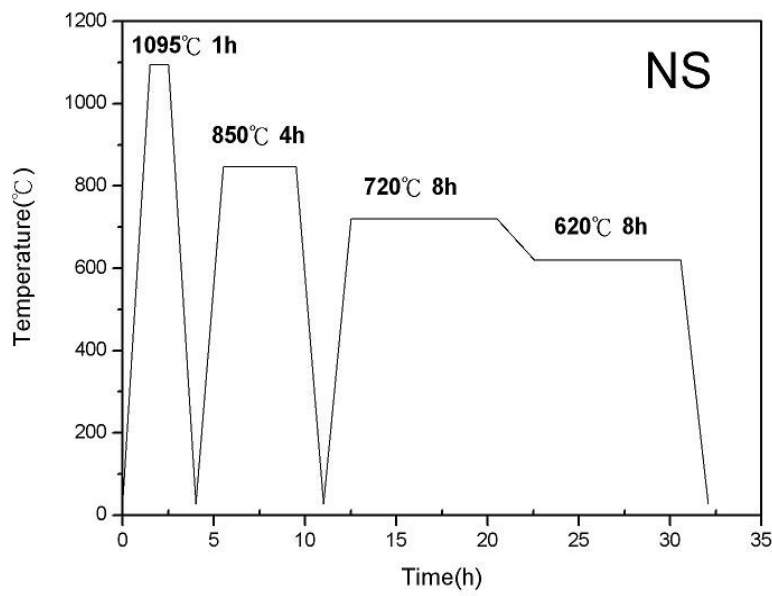

Figure2. The solution and ageing heat treatment cycle for NS samples (no zigzag grain boundary morphology); the heat treatment cycle is almost identical to that of SE samples. 


\section{Creep Tests}

Solution and ageing heat treated SE and NS samples were machined into standard test pieces for creep rupture test under a condition of $650^{\circ} \mathrm{C} / 625 \mathrm{MPa}$, the dimension of the specimen is shown in Figure 3. Comparisons of the results between SE and NS samples can indicate the effect of serrated grain boundary on creep behaviour.

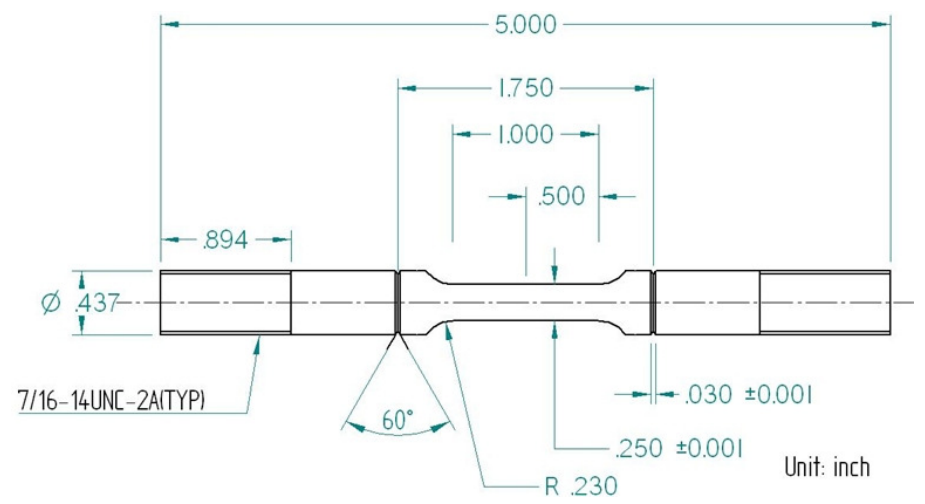

Figure 3. Dimension of test piece for creep rupture test.

\section{$\underline{\text { Hardness Test }}$}

Rockwell hardness tests were conducted on both heat treated SE and NS samples. Surfaces were polished to remove residual stresses, and then hardness tested with a 1/16 inch diamond ball, 150 $\mathrm{kg}_{\mathrm{f}}$ load. 16 test points were conducted on each sample, and then averaged [9].

\section{$\underline{\text { Microstructure Observations }}$}

Metallographic samples were prepared by mechanical grinding and polishing followed by electrolytic etching with $10 \%$ oxalic acid in water. Optical microscope and scanning electron microscope were used to observe the microstructures of heat treated samples and crept specimens. Grain size was measured by image analysis software [10].

\section{$\underline{\text { XRD and DSC Analysis }}$}

X-ray diffractometer was used to obtain characteristic peaks of heat treated SE and NS samples. The X-ray scans were collected between $20^{\circ}$ and $110^{\circ}$, with a scanning rate of $2^{\circ} / \mathrm{min}$. Differential scanning calorimetry (DSC) analysis was conducted on both heat treated SE and NS samples.

\section{Results and Analysis}

Interestingly, although solution and ageing heat treatment cycles of SE and NS were almost identical, serrated grain boundary could only be observed in the microstructure of IN718 after SE heat treatment, Figure 3; NS heat treatment did not yield zigzag grain boundary morphology, Figure 4. Figure 5 shows that average grain size of SE samples $(122 \mu \mathrm{m})$ was smaller than that of NS samples $(165 \mu \mathrm{m})$; indicating constraint to the movement of grain boundary occurred during SE heat treatment process. By SEM-EDS analysis, Figures 6 and 7 had shown $\delta$ phase was detected at the grain boundary, however, in the case of SE sample; $\delta$ phase appeared to be 
oriented along the zigzag morphology.

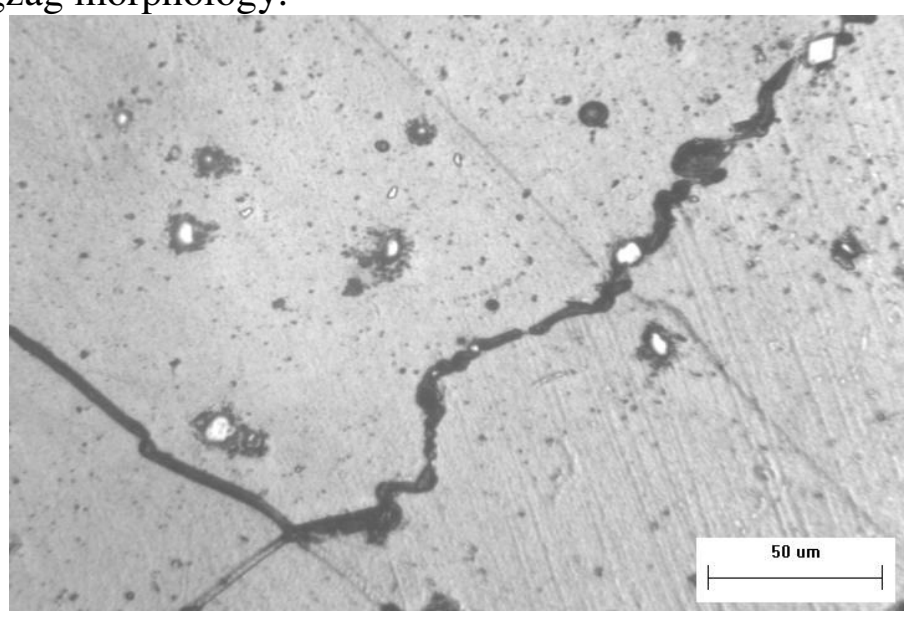

Figure 3. Optical microscope image of heat treaded SE sample. Zigzag grain boundary morphology can be observed.

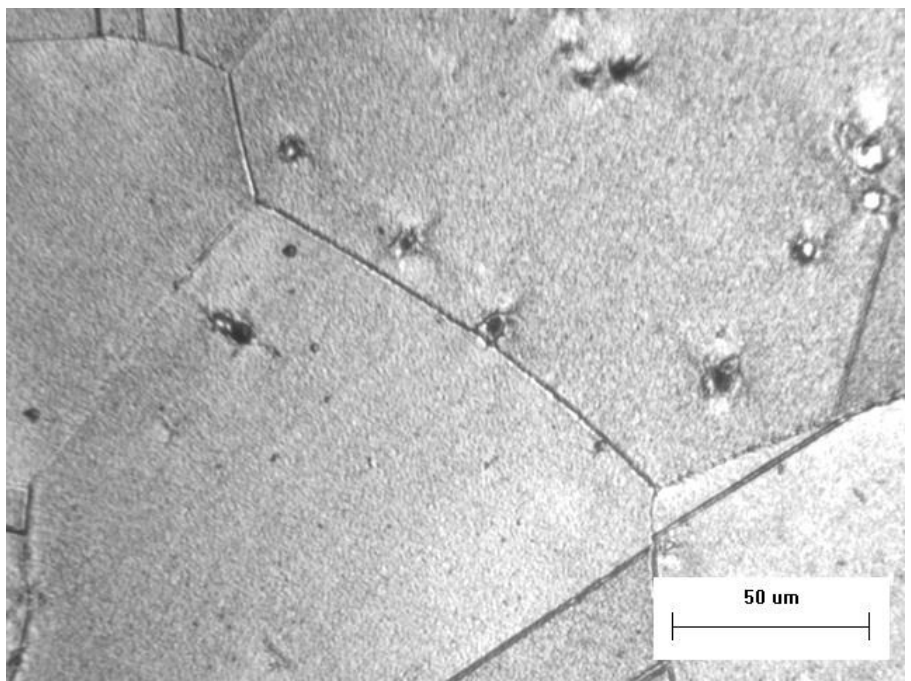

Figure 4. Optical microscope image of heat treated NS sample. There was no zigzag grain boundary morphology detected.

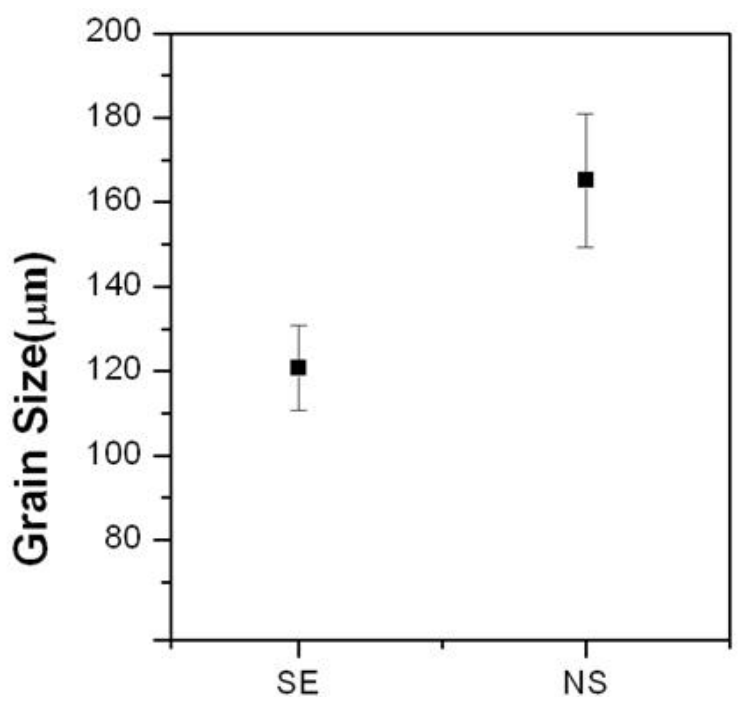


Figure 5. Average grain size in heat treated SE and NS samples were $122 \mu \mathrm{m}$ and $165 \mu \mathrm{m}$, respectively.

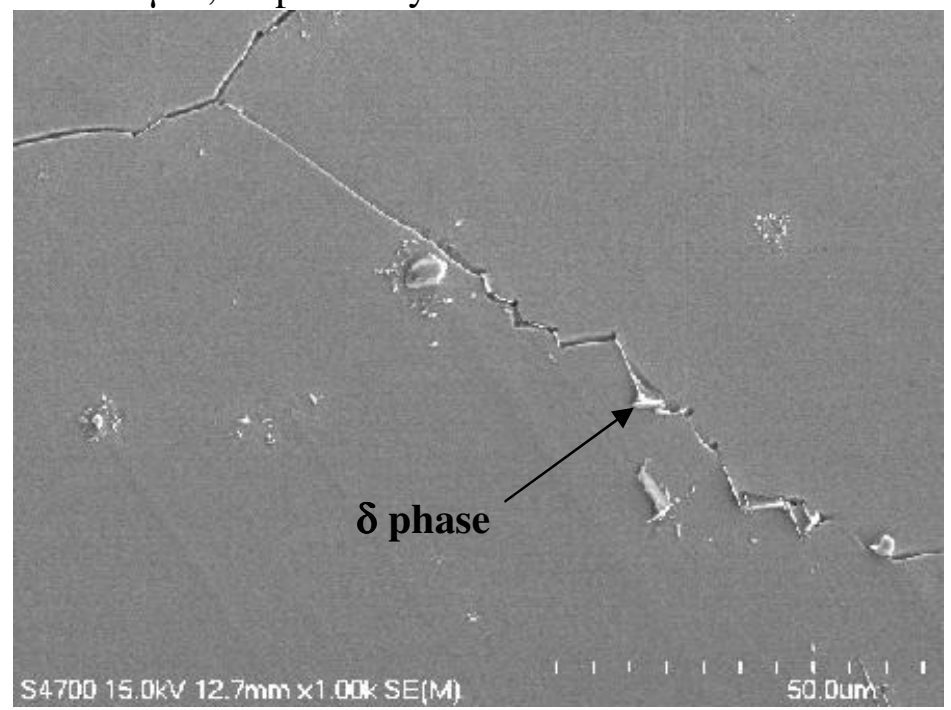

Figure 6. Scanning electron image of heat treaded SE sample. Some $\delta$ phase precipitates can be detected along with the zigzag grain boundary morphology.

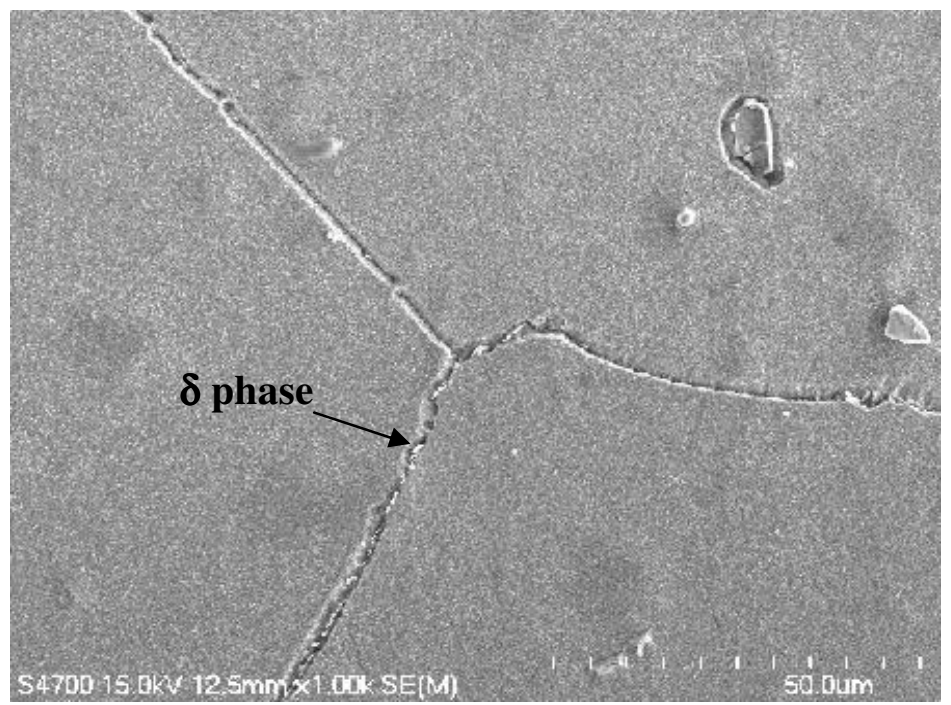

Figure 7. Scanning electron image of heat treaded NS sample. No zigzag grain boundary morphology was observed; some $\delta$ phase precipitates can be detected. 


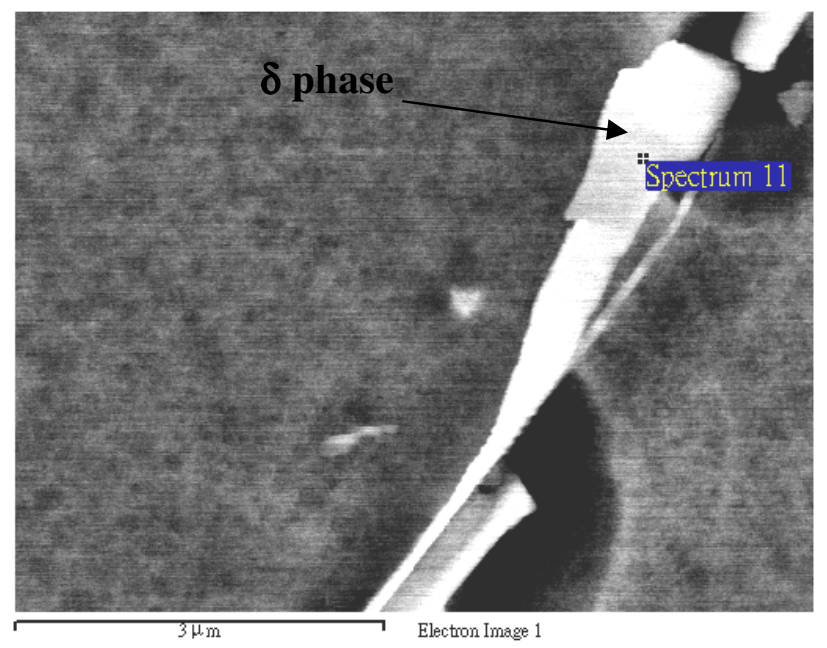

Figure $8 . \delta$ phase precipitate identified in the SE sample.

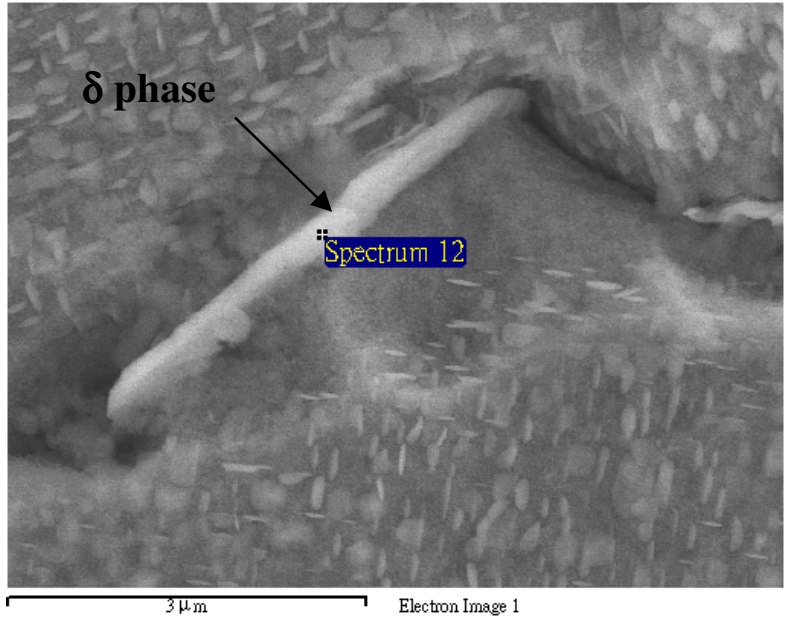

Figure $9 . \delta$ phase precipitate identified in the NS sample.

It was likely that the slow cooling from solution temperature to the ageing temperature of $850^{\circ} \mathrm{C}$ during SE heat treatment allowed the $\delta$ phase to not only precipitate but also coarsen to a sufficient size to pin the movement of grain boundary, Figure 8 . Since $\delta$ phase oriented along the close-packed plan of the matrix, zigzag grain boundary morphology can be formed. By contrast, $\delta$ phase formed during the NS heat treatment remained small in size within the grain boundary, Figure 9, so it appeared that $\delta$ phase was formed during the ageing treatment at $850^{\circ} \mathrm{C}$ and did not affect the morphology of the grain boundary. X-ray analysis, Figure 10, indicated main phase constituents in both SE and NS samples were the same. 

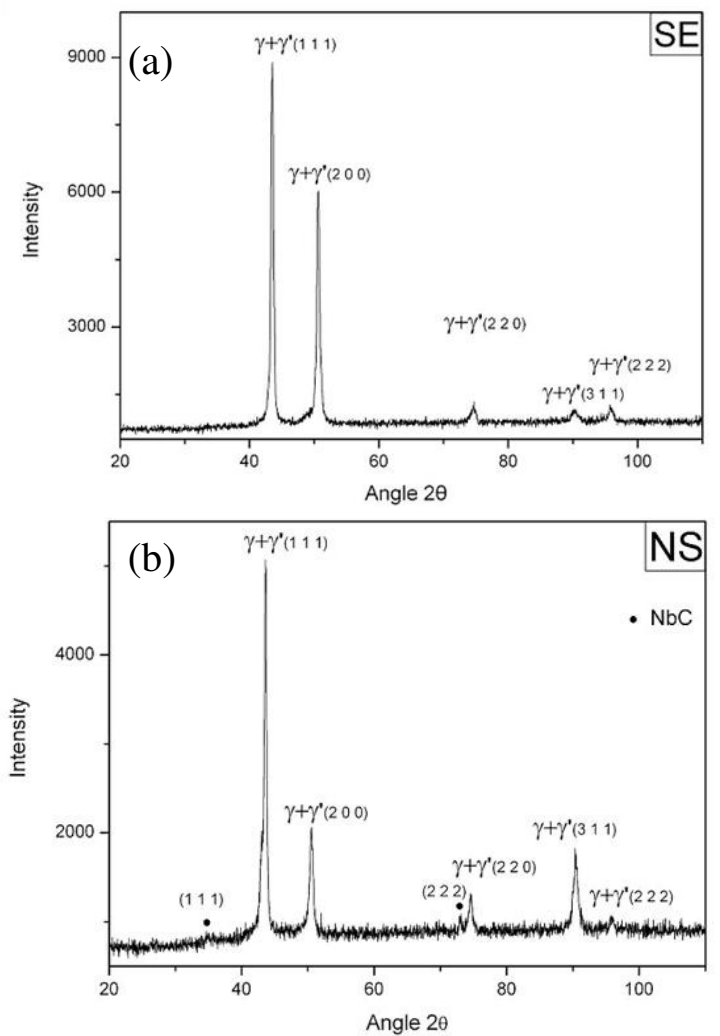

Figure 10. X-ray diffraction analysis (a) SE sample, (b) NS sample, results indicate both of them have almost identical phase constituents.

The amount of $\delta$ phase could be too little to be detected by XRD.

Results from the differential scanning calorimetry analysis, Figure 11, confirmed that main phase constituents were identical with possibly little degree of difference in the volume fraction to result a slight difference in the heat flow during DSC. So, any difference in the creep responses between SE and NS samples can be attributed by the serrated grain boundary. Figure 12 shows creep curves under $650^{\circ} \mathrm{C} / 625 \mathrm{MPa}$ for both samples. Interestingly, SE sample exhibited a creep rupture life of 1600 hours and it outperformed that of the NS sample by 400 hours. So, the serrated grain boundary was able to enhance the creep resistance of the SE sample. Further analysis revealed that $\mathrm{SE}$ and NS samples reached minimum creep strain rates of $1.8 \times 10^{-7} \mathrm{~s}^{-1}$ and $1.9 \times 10^{-7} \mathrm{~s}^{-1}$ after 300 hours, respectively, and crept similarly during early stage of creep, Figure 13, which focuses the 600 hours creep curves of Figure 12. 


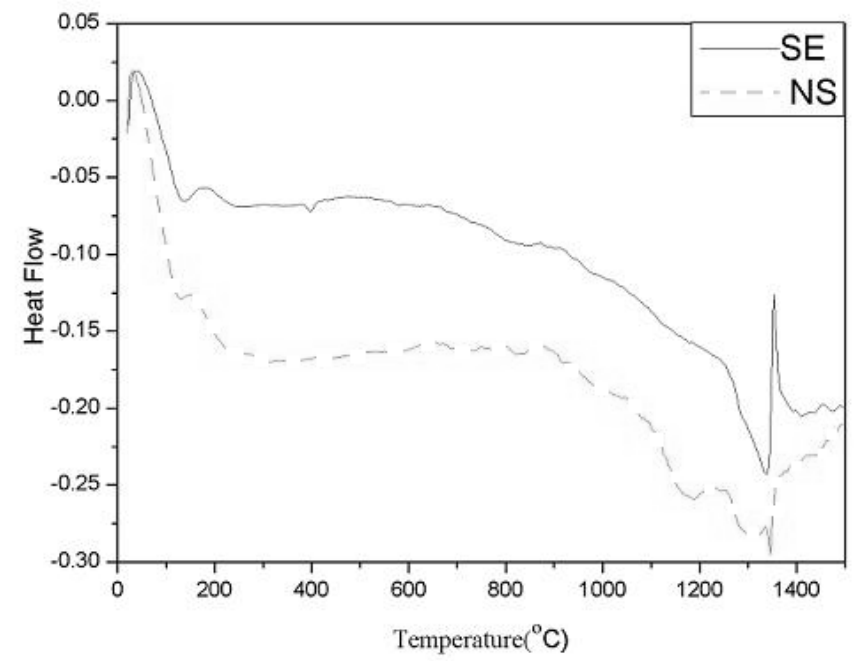

Figure 11. Differential scanning calorimetry analysis. The smooth heat flow curves of SE samples indicate its rate of heat release is slightly different from that of NS sample.

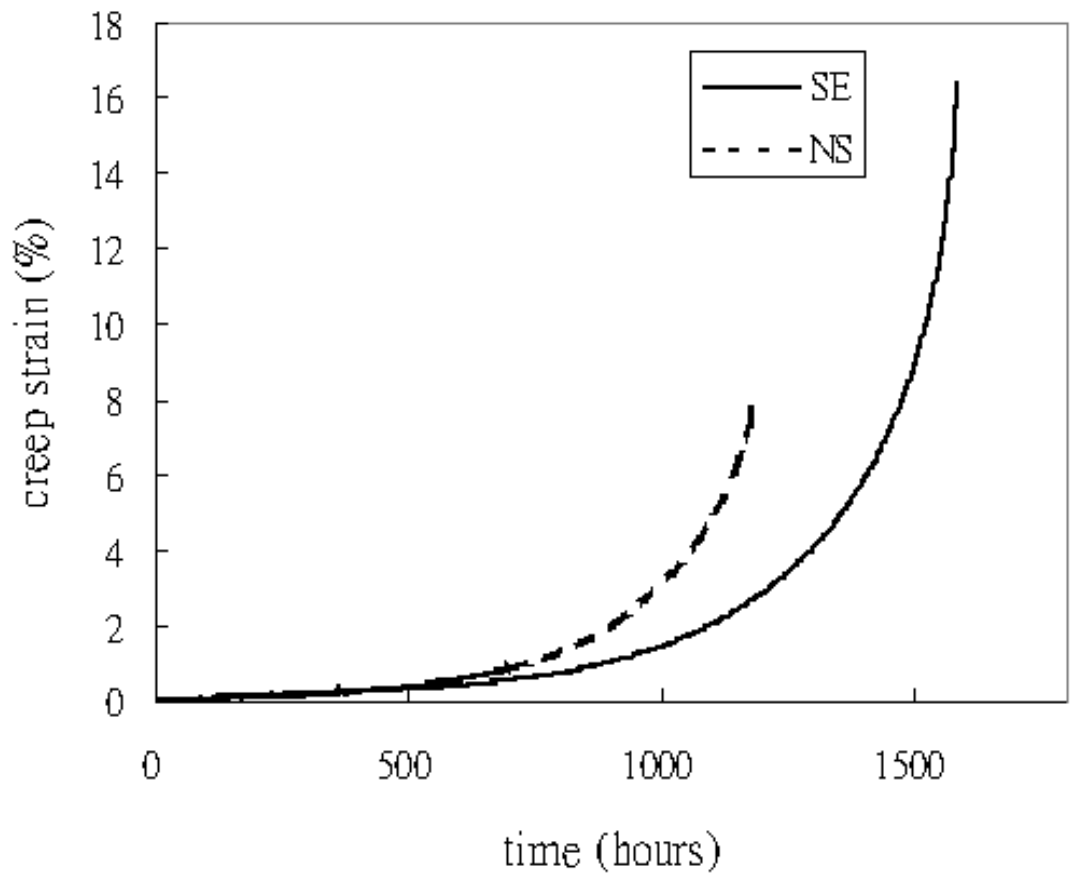

Figure 12. Creep curves under $650^{\circ} \mathrm{C} / 625 \mathrm{MPa}$. SE sample outperformed that of NS sample by additional creep rupture life of 400 hours. 


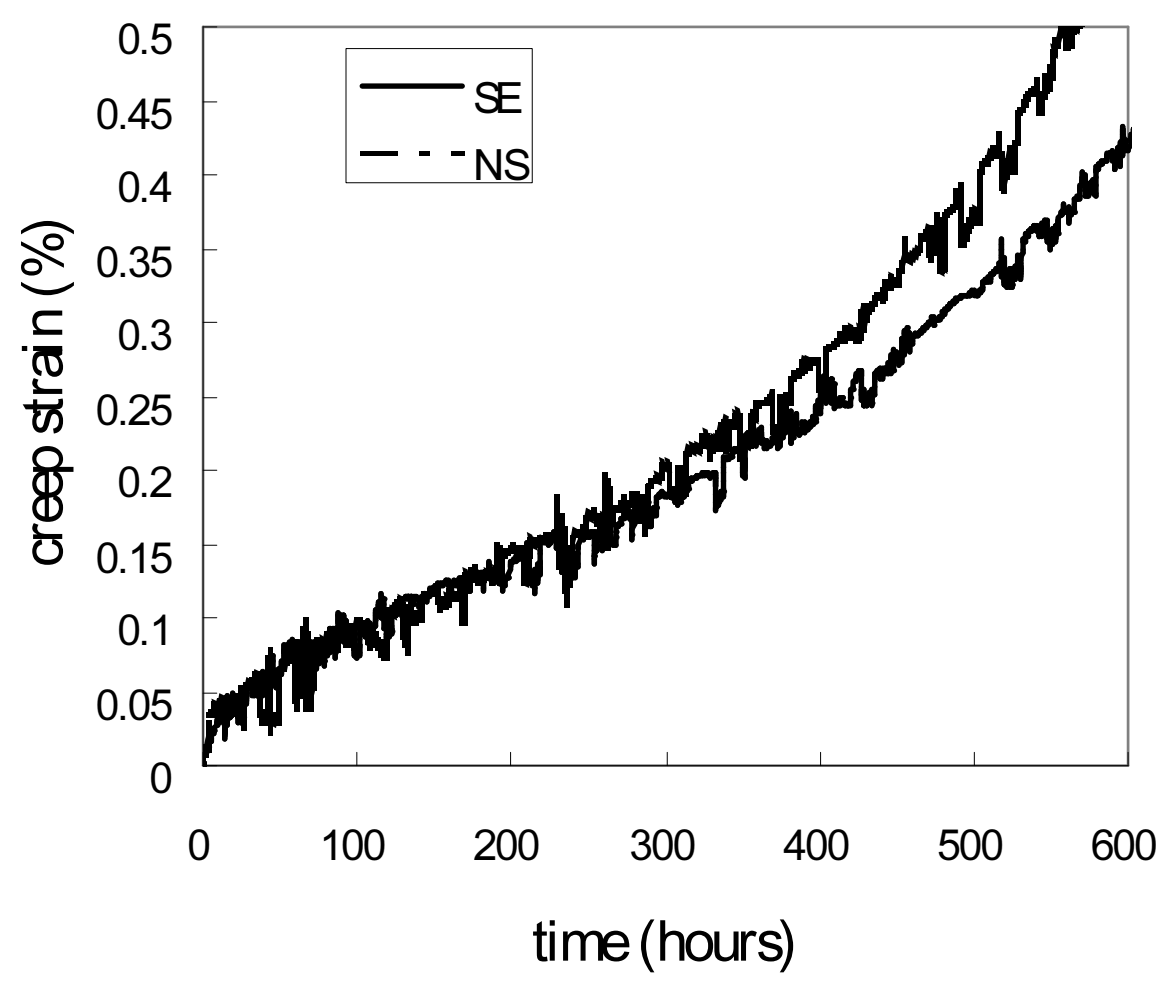

Figure 13. Creep curves under $650^{\circ} \mathrm{C} / 625 \mathrm{MPa}$. SE sample crept similarly to the NS sample during early stage of creep until 300 hours, where both alloys entered the tertiary creep region with different strain rates.

The Rockwell hardness of SE sample was almost the same as that of the NS sample, Figure 14. This result confirmed results of SEM, XRD and DSC, that both samples had almost identical microstructure and phase constituents, except that the grain boundary of SE sample had zigzag morphology.

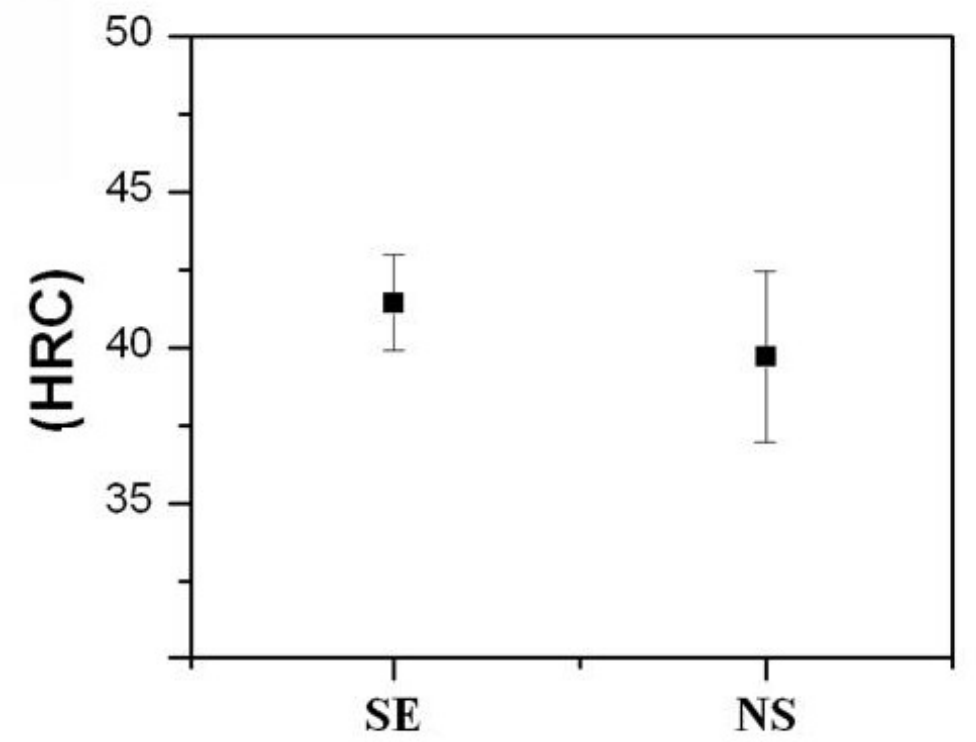

Figure 14. Results of Rockwell hardness test for SE and NS samples were similar. 


\section{Discussions}

It is evident that the creep ruptured life could be extended by serrated grain boundary, Figure 12. Both SE and NS samples crept similarly during the primary and secondary creep regions until 300 hours, Figure 13. Because SE and NS samples were identical in compositions and phase constituents, Figure 13 suggested that zigzag grain boundary morphology could not affect primary and secondary creep regions, but it had a significant impact on the tertiary creep behaviour, Figure 12. Possibly the zigzag morphology could hinder the sliding of the grain boundary during the tertiary creep, and resulted lower creep strain rate of SE sample, hence the creep rupture life could be longer. The present study also suggested that precipitation and growth of $\delta$ phase during the transition from $1095^{\circ} \mathrm{C}$ to $850^{\circ} \mathrm{C} / 4$ hours was responsible for the formation of zigzag grain boundary by pinning the movement of grain boundary during ageing treatment at $850^{\circ} \mathrm{C}$. On the other hand, $\delta$ phase in NS sample was smaller in size and did not attribute to the pinning of grain boundary. This result indicated that the timing of $\delta$ phase precipitation is critical for the formation of zigzag grain boundary morphology. This analysis was confirmed by microstructure observations, Figures 6 9. Although there appeared to be very little difference in terms of morphology of $\delta$ phase in NS and SE samples, Figures 8 and 9, the size of $\delta$ in SE was larger than that in NS significantly, Figures 6 and 7. Since both XRD and DSC analysis indicated that phase constituents in both samples were very similar, Figures 10 and 11, the grain size of the SE sample was measured to be slightly smaller than that of the NS sample, Figure 5. Typically, smaller grain size would result a shorter high temperature creep life due to greater effect of grain boundary sliding. Interestingly, SE sample performed better than NS against creep deformation in present study; hence the serrated grain boundary had overcome the shortfall of smaller grain size and yielded an impressive improvement in creep rupture life.

Applying IN718 for structural application, serrated grain boundary can be useful to prolong the creep rupture life. By contrast to traditional alloying method, which is costly, to yield significant benefit on mechanical property, the present study shows that minor adjustment in heat treatment is able to yield an improvement in creep rupture life by over $30 \%$.

\section{Conclusions}

Following conclusions can be summarized from the present study:

1. SE heat treatment could result the formation of serrated grain boundary.

2. $\delta$ phase were precipitated in both SE and NS samples, however, $\delta$ phase in SE sample was larger in size and was able to effect the movement of grain boundary to result smaller grain size and serrated grain boundary.

3. Serrated grain boundary did not affect the primary and secondary creep behaviours; however, it could lower the creep strain rate in the tertiary creep region, and prolong the creep life significantly.

\section{Acknowledgements}

This work was supported by National Science Council of Taiwan under grant number NSC 982623-E-214-002-D. SEM, X-ray and DSC were conducted at MANA-Laboratory of Department of Materials Science and Engineering, I-Shou University. Discussions with Prof. Beddoes at Carleton University, Canada, are very much appreciated. 


\section{References}

1. E.O. Ezugwu, J. Bonney, and Y. Yamane, "An Overview of the Machinability of Aeroengine alloys,” Journal of Materials Processing Technology, 134 (2003), 233-253.

2. C.F. Miller, G.W. Simmons, and R.P. Wei, "Mechanism for Oxygen Enhanced Crack Growth in Inconel 718," Scripta Materiala, 44 (2001), 2405-2410.

3. D.-H. Kim and J.-H. Kim, "Stress Rupture Characteristics of Inconel 718 Alloyfor Ramjet Combustor," Materials Science and Engineering A, 483-484 (2008), 262-265.

4. R.J. Mitchell, H.Y. Li, and Z.W. Huang, "On the Formation of Serrated Grain Boundaries and Fan Type Structures in an Advanced Polycrystalline Nickel-base Superalloy," Journal of materials processing technology, 209 (2009), 1011-1017.

5. A. Wisniewski and J. Beddoes, "Influence of Grain-Boundary Morphology on Creep of a Wrought Ni-base Superalloy,” Materials Science and Engineering A, 510-511 (2009), 266-272.

6. D.H. Ping, Y.F. Gu, C.Y. Cui, H. Harada, "Grain Boundary Segregation in a Ni-Fe-based (Alloy 718) superalloy," Materials Science and Engineering A, 456 (2007), 99-102.

7. H.U. Hong, I.S. Kim, B.G. Choi, M.Y. Kim, C.Y. Jo, "The Effect of Grain Boundary Serration on Creep Resistance in a Wrought Nickel-based Superalloy," Materials Science and Engineering A, 517 (2009), 125-131.

8. C.-M. Kuo, Y.-T. Yang, H.-Y. Bor, C.-N. Wei, and C.-C. Tai, "Aging effects on the microstructure and creep behavior of Inconel 718 superalloy," Materials Science and Engineering A, 510-511 (2009), 289-294.

9. ASTM E18, "Standard Test Method for Rockwell Hardness and Rockwell Superficial Hardness of Metallic Materials," Annual Book of ASTM Standard, vol. 03.01.

10. ASTM E122, "Standard Test Methods for Determining Average Grain Size," Annual Book of ASTM Standard, vol. 03.01. 